\title{
HUMAN MOBILITY DURING THE COVID-19 PANDEMIC IN WESTERN BALKAN COUNTRIES
}

\author{
Srđan Damjanović \\ Faculty of Business Economics Bijeljina, University of Eastern Sarajevo \\ srdjan.damjanovic@fpe.unssa.rs.ba \\ Predrag Katanić \\ Faculty of Business Economics Bijeljina, University of Eastern Sarajevo \\ predrag@telrad.biz \\ Vesna Petrović \\ Faculty of Business Economics Bijeljina, University of Eastern Sarajevo \\ vesna.petrovic@fpe.unssa.rs.ba
}

\begin{abstract}
At the end of 2019, a new coronavirus appeared in the Chinese province of Wuhan, causing the appearance of the disease COVID-19. The disease spread very quickly to other countries in the world, including the Balkans. The governments of many countries have decided to combat the spread of the COVID-19 virus in the community through social distancing measures. Decisions to ban the movement of people were easy to make, but they were very difficult to implement and enforce in practice. Some of the countries monitored their citizens through various applications installed on smartphones. This led to criticism by many NGOs, as they felt that this violated basic human rights of freedom of movement and privacy. Some lawsuits were even filed in the courts because the citizens felt that they were denied rights guaranteed by the respective constitution.

Google uses the ability to monitor all those citizens around the world on a daily basis who use smartphones or handheld devices, which provide the option to record the "location history" of the users. This is possible for them, since most people have voluntarily agreed to this option on their devices. In early 2020, Google began publishing global mobility data on a daily basis through a report called "Community Mobility Reports". The report shows the percentage change in human activity at six grouped locations. Data obtained in the reference days before the outbreak of the COVID-19 pandemic are used as a basis for comparison.

In this paper, we studied the dynamics of human mobility during the COVID-19 pandemic in 7 countries of the Balkans: Bosnia and Herzegovina, Serbia, Croatia, North Macedonia, Bulgaria, Greece, and Romania. For Montenegro and Albania Google did not provide data on human mobility. We present the processed data graphically. For all examined countries, we statistically analyzed the obtained data and presented them in a table.
\end{abstract}

Keywords: Mobility, Data, Balkan

JEL classification: $015, \mathrm{~J} 61$

\section{INTRODUCTION}

At the end of 2019, a new coronavirus appeared in China in the Chinese province of Wuahn, causing the appearance of the disease termed COVID-19. In order to stop the further spread of the disease, China locked down this province on January 23, 2020. However, this disease quickly began to spread to other countries around the world. The first cases in Europe were recorded in the second half of January 2020. The rapid spread of the COVID-19 pandemic 
has produced several different effects around the world. The governments of most countries have begun to apply various special measures to stop the spread of the virus, because the health systems were on the verge of collapse. Likewise, some countries in parts of Asia and Southern Europe have implemented very drastic policies of lockdowns, prohibiting the movement and gathering of large numbers of people. It was also recommended that all employers, who could feasible undertake, organize work from home and most educational institutions have switched to teaching classes online. In contrast, a small number of countries did not apply a strict approach to banning the movement and gathering of people (examples being Sweden and Belarus). At the beginning of this pandemic, there were no vaccines to prevent this disease. That is why the World Health Organization has recommended that the best strategy to fight the COVID-19 disease is to prevent the transmission of the virus by social distancing. This has been a major problem for most countries, as most social and economic activities are based on direct interaction between people. Each ban on physical interaction and gathering of people also produced huge economic losses for all countries involved. Ideally, the state could monitor the movement and contacts of people 24 hours a day. States have begun to develop various methods for tracking people. Some of the countries monitored their citizens through various applications installed on mobile phones. This led to protests by many NGOs, as they felt that this violated basic human rights and presented an intrusion of privacy. In some countries, lawsuits have also been filed before the courts, as citizens felt that the government's dictates denied their constitutionally guaranteed rights.

In 2020, Google began publishing data on global mobility daily through a report named Community Mobility Reports (CMR). This report contains collected data from 135 countries of the world, starting from 15.2.2020. This report includes some statistics, which aim to promote studies, which can help in the fight against COVID-19 disease. Furthermore, we believe that they can also be used to analyze economic trends. Google's CMR aggregates the data of those individuals who access the Google app with smartphones or handheld devices, which grants the option to record "location history." The physical presence of an individual user and the time spent in certain categories of location are compared, to determine certain activity characteristics of the participants. The data are categorized into six discrete categories, which can be summarized as follows:

- retail and recreation (restaurants, cafes, shopping malls, museums, libraries, cinemas);

- pharmacies and grocery stores (pharmacies, grocery stores, agricultural markets);

- $\quad$ parks (city parks, national parks, public beaches, marinas, camps, dog parks);

- transit stations (public transport hubs such as metro, bus and train stations, seaports, taxi stands, motorway rest areas);

- workplaces;

- $\quad$ and places of residence.

The CMR provides a percentage change in human activity for each listed site category and compares it to total the activity in the reference days prior to the onset of COVID-19 (a fiveweek period running from January 3, 2020 to February 6, 2020). Daily activity fluctuations are compared to the corresponding reference day. For example, the data for Mondays are compared with the corresponding Mondays in the reference set. The values shown thus represent a relative percentage change compared to the reference days, rather than an absolute number of visitors. With the help of these data, it is easy to see whether the population in a country had complied with the measures physical distancing, which were adopted by the governments of those respective countries. The CMR report is provided for each country individually or combined for the entire world in a CSV extension file. This file contains data written in plain text and, contains a comma-separated list of data. Each row of data is linked to one date. For some countries, there is data for the whole country only, while for other countries data are given broken down by regions and cities. In this paper, we took data only 
at the whole country level. CSV files can be opened using most programs that work with text and tables. We loaded this data into a Microsoft Excel worksheet via the Data menu of the Get External Data submenu and using the From Text command.

In this paper, we studied the dynamics of human mobility during the COVID-19 pandemic in 7 countries in the Balkans: Bosnia and Herzegovina, Serbia, Croatia, Northern Macedonia, Bulgaria, Greece and Romania. There is no CSV file for Albania and Montenegro, so it is not possible to monitor the mobility of people in these two countries. The data were observed starting from February 15, 2020 until July 1, 2021 years. In some countries, values for some of the 6 observed parameters were missing for certain days in the observed period, if human activity at that location was too low on a certain day and therefore the anonymity threshold set by Google was not able to be achieved.

\section{GRAPHS OF HUMAN MOBILITY IN 7 BALKAN COUNTRIES}

In this paper, we have processed and presented data on the dynamics of human mobility during the COVID-19 pandemic in seven Balkan countries starting from February 15, 2020 until July 1, 2021 for six different location categories. For each country, we made attendance fluctuation graphs for four categories of locations: parks, transit stations, workplaces, and housing facilities. The X-axis covers the months from February 2020 to June 2021. The Yaxis shows the percentage change in attendance of the observed locations. We left out the data from the retail and recreation category, as well as pharmacies and grocery stores, because we wanted the diagrams to be as uncluttered as possible. Observing the obtained graph for each country, we noticed that on weekends and on public and religious holidays, large peaks in attendance changes appeared. To reduce these peaks, we excluded data for all Saturdays and Sundays, as well as non-working holidays Christmas, New Year's Day, May $1^{\text {st }}$, and certain non-working days corresponding to public holidays in individual countries. Figure 1 shows diagrams of the changes in mobility measured as attendance at four locations in Bosnia and Herzegovina.

Figure 1: Bosnia and Herzegovina changes in mobility of 4 locations in 2020 and 2021

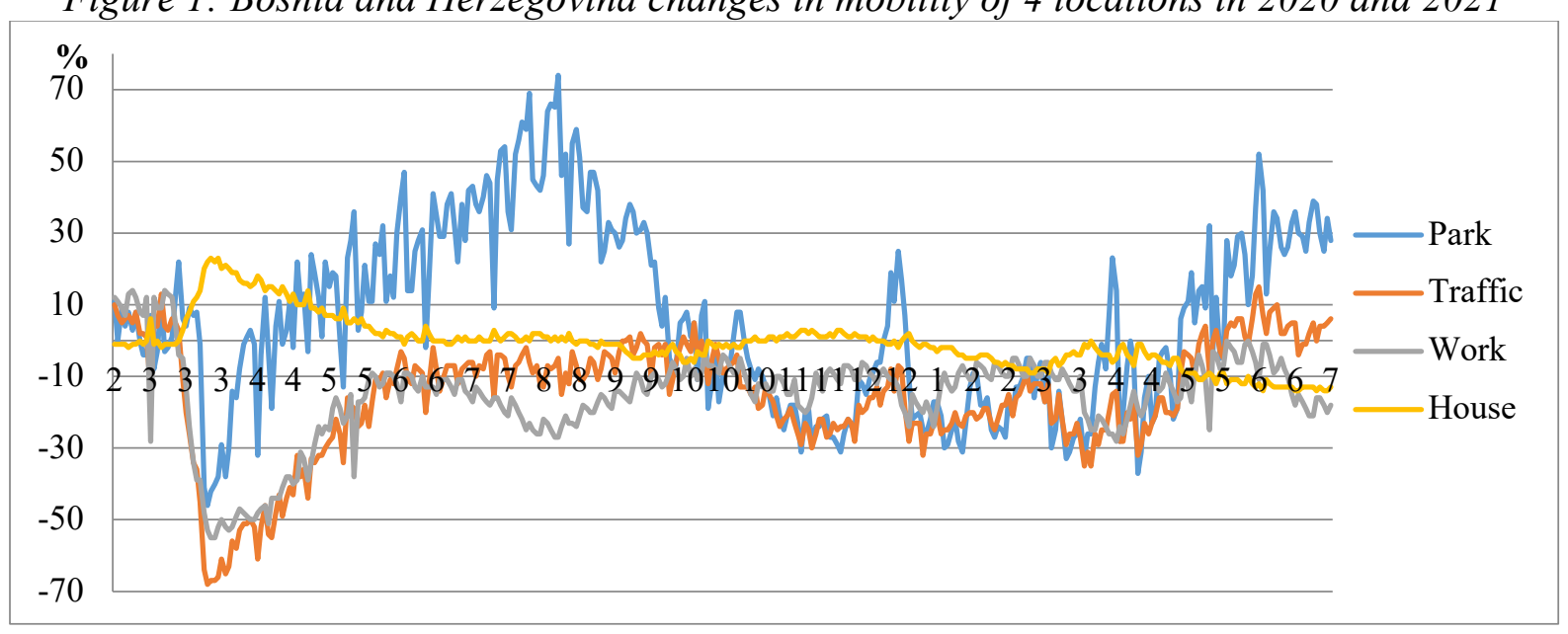

(Source: Authors)

For Bosnia and Herzegovina, it is very easy to see a large decline in the movement of people in March 2020, and the largest declines are observed in the categories of work and traffic. In the same period, a sudden increase in the time people spent at home can be seen. This is exactly the period when the first instance of an increased number of infected people in Bosnia and Herzegovina emerged. Following the "Work" curve, it can also be seen that the second 
period of declining job attendance occurred in July and August 2020, but this can be attributed to people taking vacations rather than an increase in the number of patients. This is confirmed by the "Park" curve, because it is during this period that the largest increase in attendance at parks and places of leisure takes place. Following the "Work" curve, it can be seen that the third period of declining job attendance occurred in March and April 2021.

Figure 2 shows graphs of the changes in mobility in terms of attendance at four locations in Serbia. We can see the first significant drop in the people's movements was in March 2020. Following the "Work" curve, it can be seen that the second period of declining work attendance occurred in December 2020 and January 2021. The third period of declining work attendance occurred in March and April 2021.

Figure 2: Serbia changes in mobility of 4 locations in 2020 and 2021

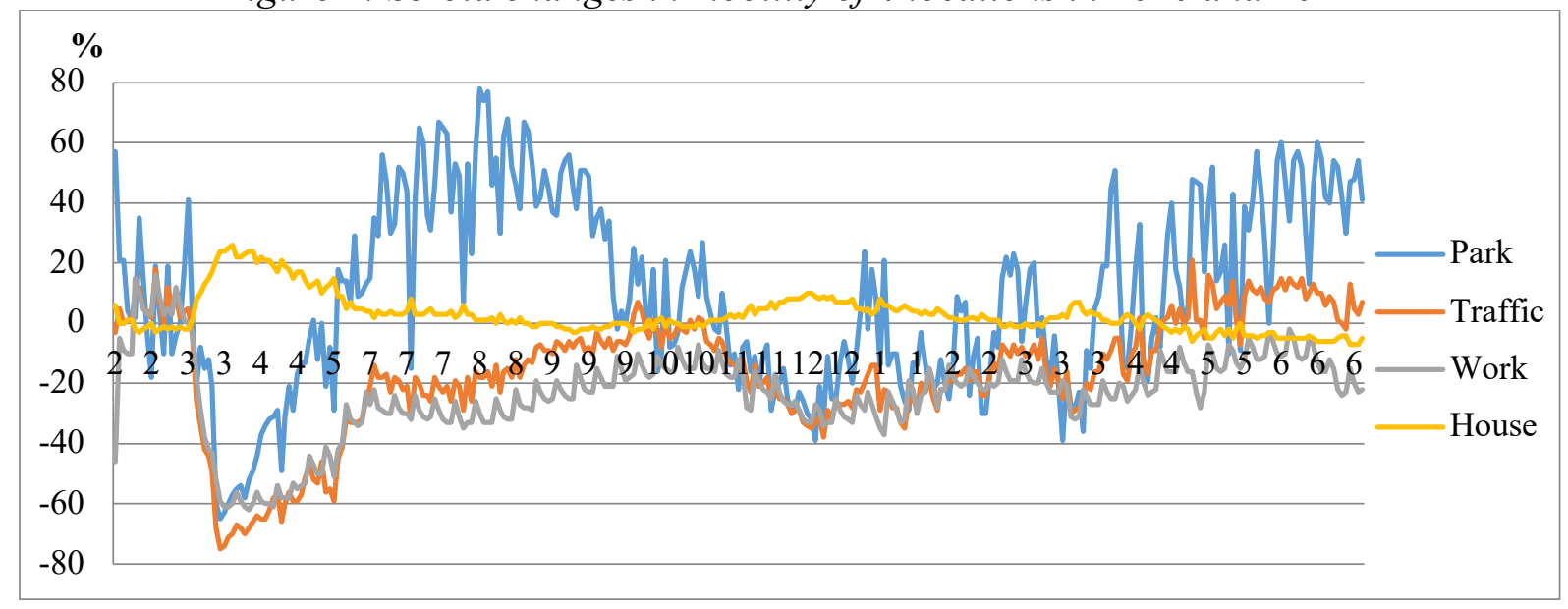

(Source: Authors)

Figure 3 shows graphs of changes in mobility in terms of attendance at four locations in Northern Macedonia. Comparing the "Work" curve with other countries, it can be seen that peaks appear periodically. By observing each individual data, we noticed that these peaks appear periodically for each Friday. We presume that the cause of these peaks lies in inadequate data for the Friday weekday in the reference period before the pandemic.

Figure 3: North Macedonia changes in mobility of 4 locations in 2020 and 2021

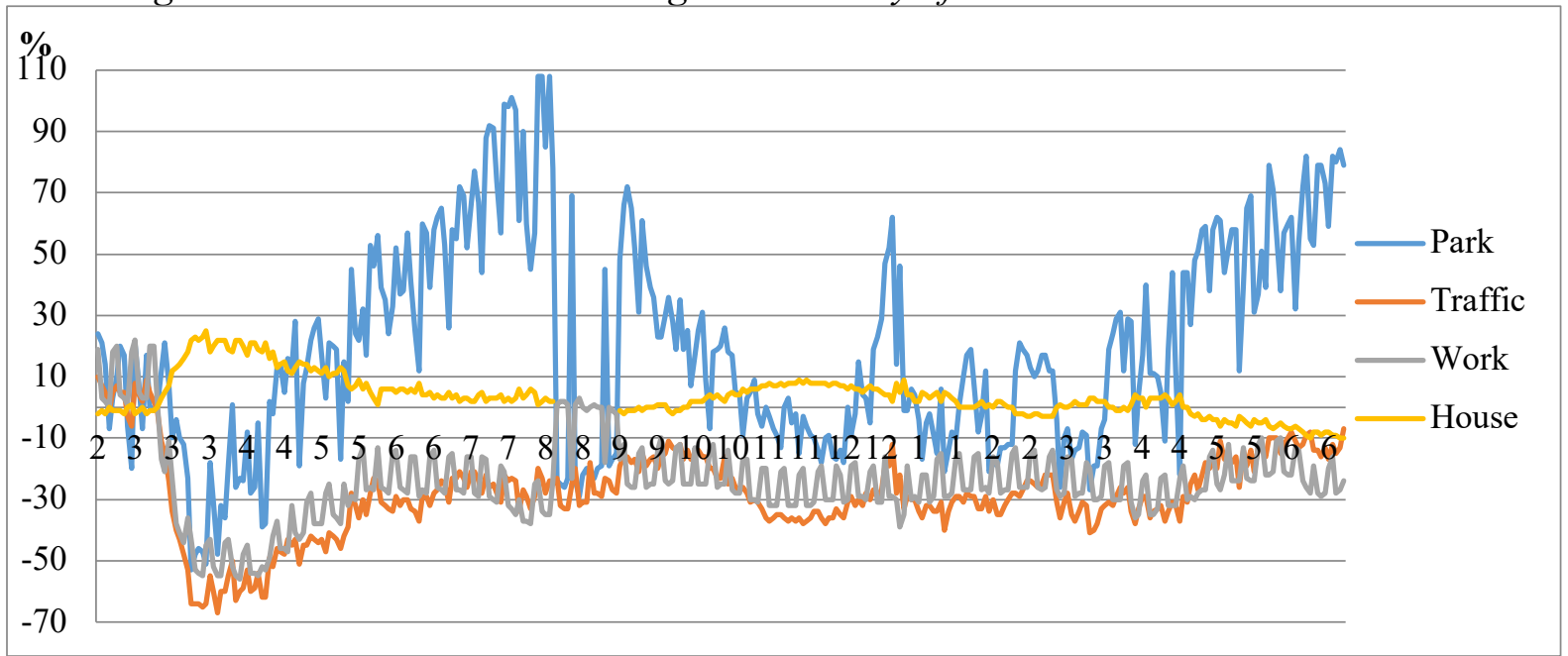

(Source: Authors) 
Figure 4 shows graphs of changes in attendance at four locations in Croatia. The diagram shows a sharp increase in attendance of the "Park" category in the period of June, July, August, and September of 2020 of up to $500 \%$ compared to the reference period before the pandemic. This is grasped by the fact that in this period the Croatian coast was visited many tourists from a large number of European countries. Google registered the movement of all these people on the territory of Croatia and added their impact to the total number of citizens of Croatia. A similar tendency of a sharp increase in the number of tourists in the period of June, July, August, and September of 2020 can be seen in Greece and Bulgaria.

Figure 4: Croatia changes in mobility of 4 locations in 2020 and 2021

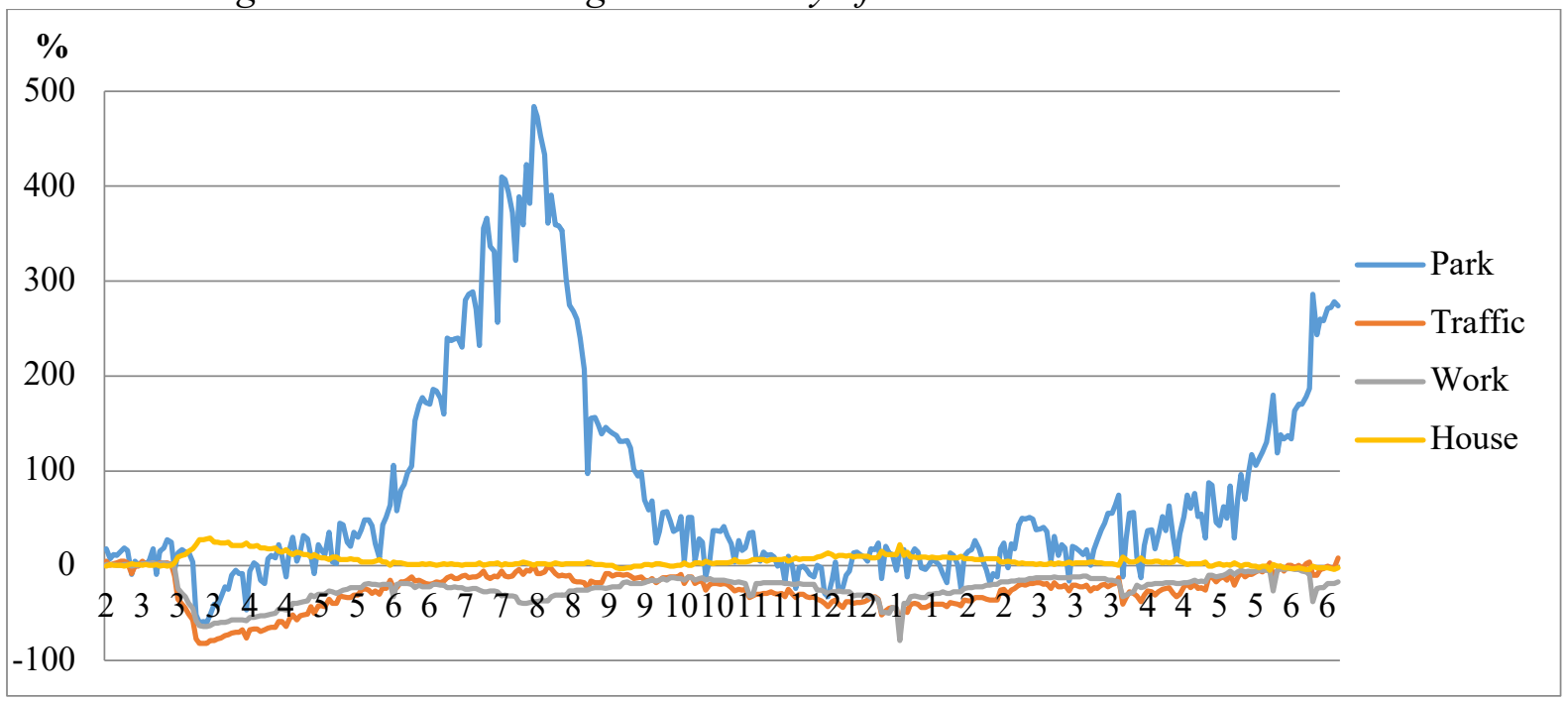

(Source: Authors)

Figure 5 shows graphs of changes in attendance at four locations in Greece. Looking at the "Park" curve, it can be assumed that Greece was visited by about 20\% more tourists in June 2021 than in the same period in 2020. To confirm this presupposition, it is necessary to compare official data from the tourism association, and that could be the subject of another paper.

Figure 5: Greece changes in mobility of 4 locations in 2020 and 2021

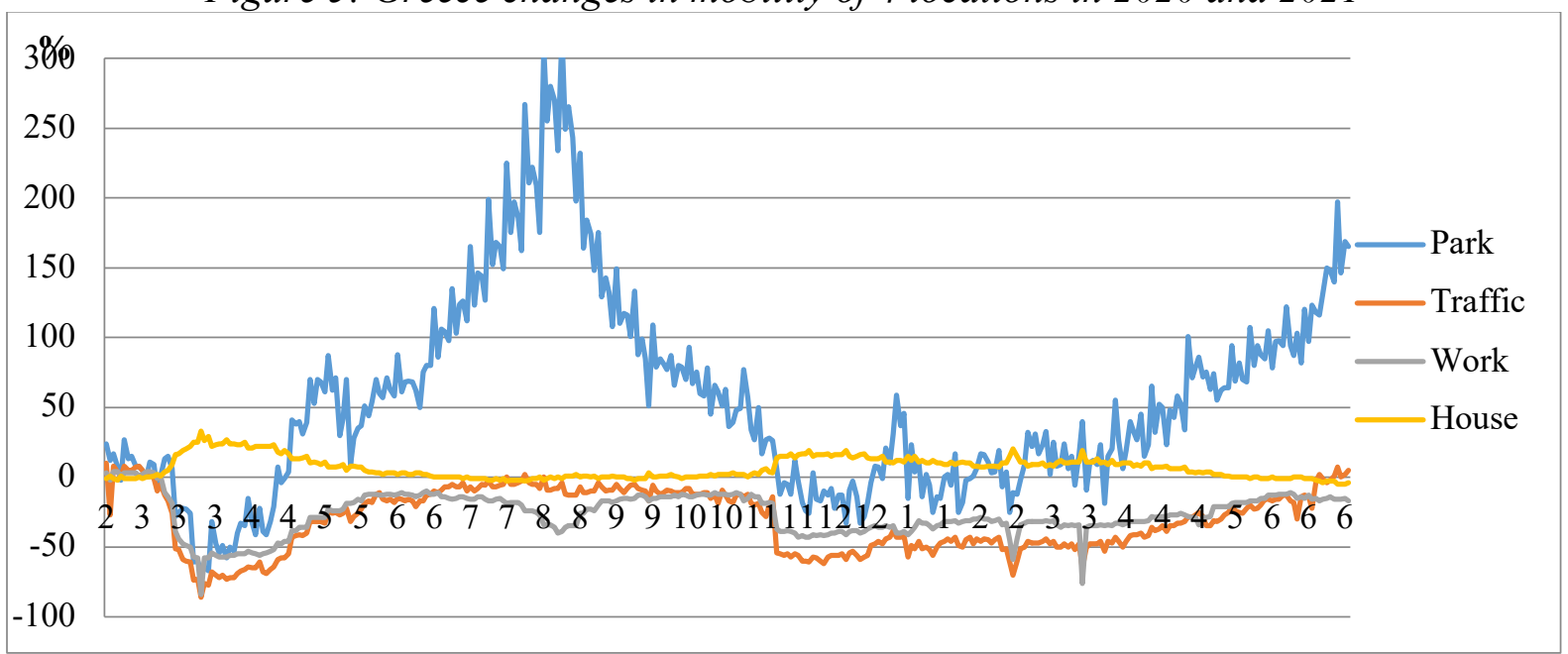

(Source: Authors) 
Figure 6 shows graphs of changes in attendance at four locations in Bulgaria. We can see the first big drop in peoples' movements occurring in March 2020. Following along the "Work" curve, the second period of declining work attendance occurred in November and December 2020. The third period of declining work attendance occurred in March and April 2021.

Figure 6: Bulgaria changes in mobility of 4 locations in 2020 and 2021

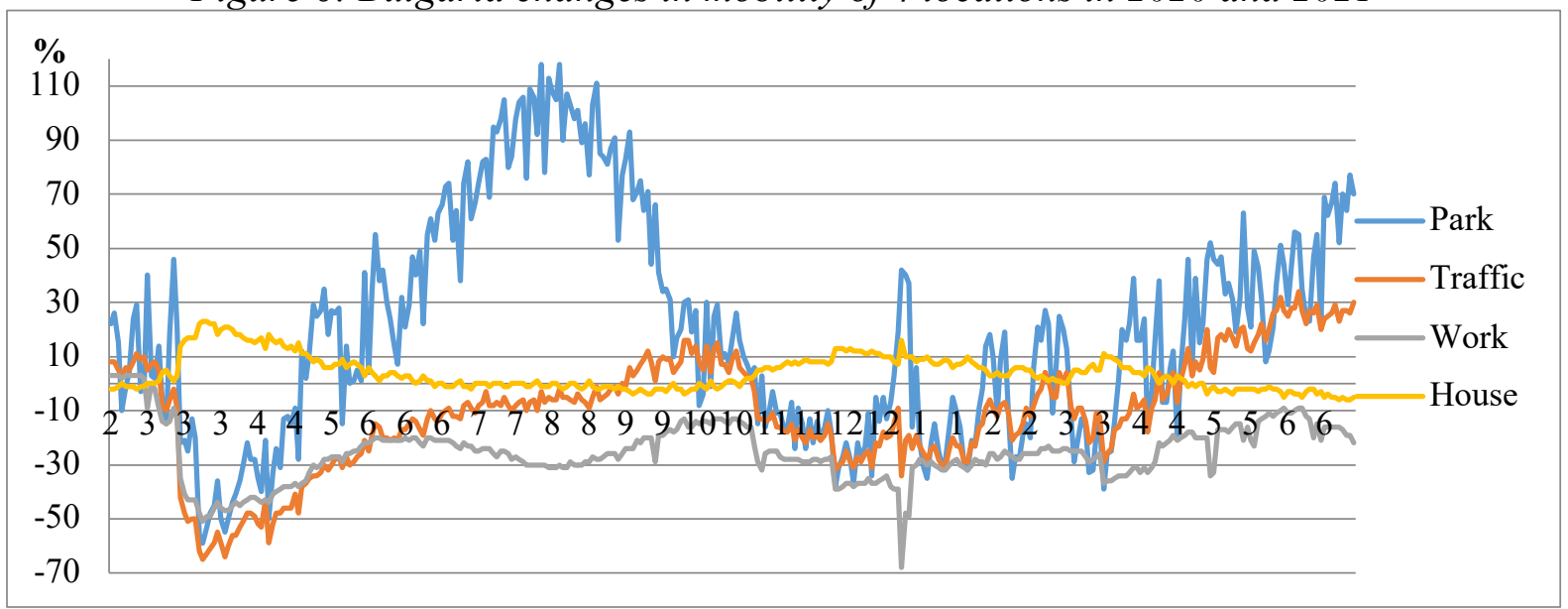

(Source: Authors)

Figure 7 shows graphs of changes in attendance at four locations in Romania. Comparing the "Work" curve with other countries, it can be observed that peaks appear periodically, as was the case in Northern Macedonia for every Friday. We assume that the cause of these peaks is inadequate data for the Friday weekday in the reference period before the pandemic.

Figure 7: Romania changes in mobility of 4 locations in 2020 and 2021

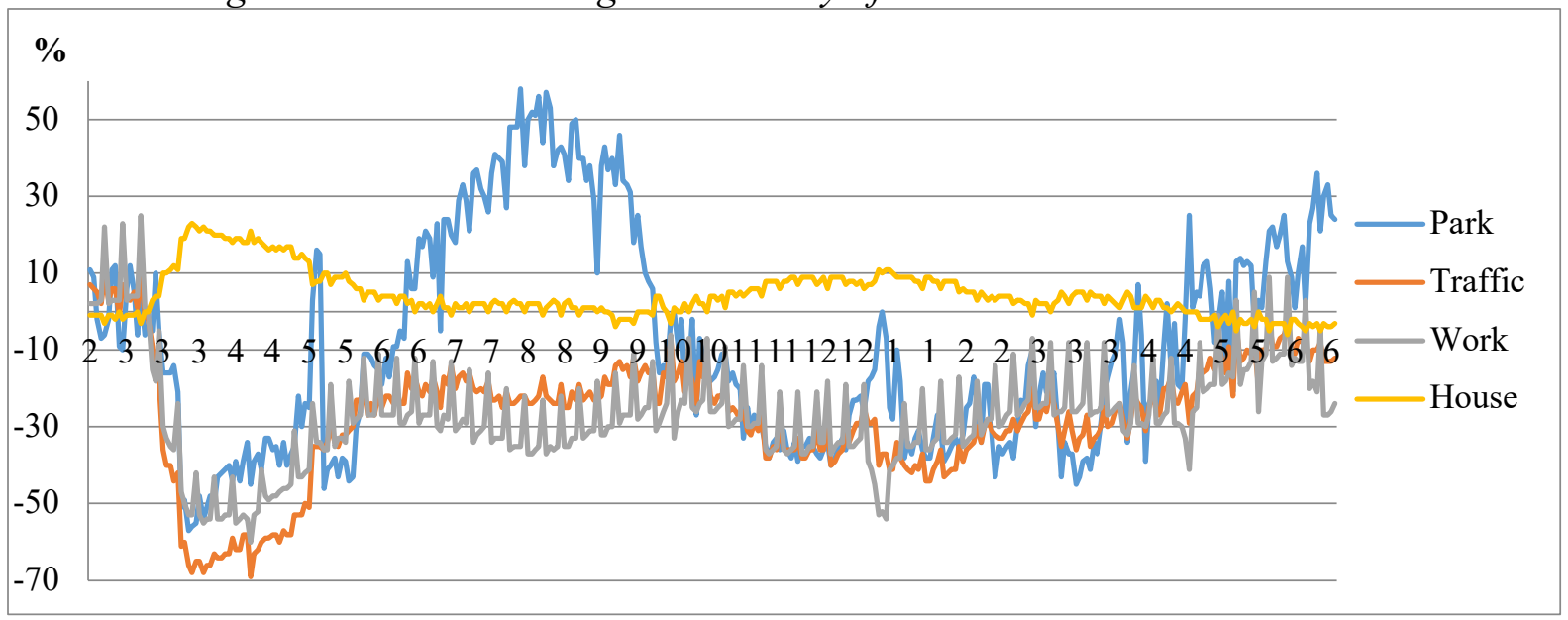

(Source: Authors)

\section{COMPARISON OF HUMAN MOBILITY IN 7 BALKAN COUNTRIES}

In this part of the paper, data on citizen mobility at six grouped locations in seven Balkan countries are statistically dealt with. Data for all Saturdays, Sundays, non-working days Christmas, New Year's and public holidays in individual countries have been omitted.

Table 1, Table 2 and Table 3 for the seven Balkan countries for each of the six different locations illustrate six different statistical parameters of human mobility data starting from 
February 17, 2020 and going through July 1, 2021. The abbreviations in this table for the observed statistical parameters are:

- Avg - Average value of percentage change in attendance;

- SD - Standard deviation of percentage change in attendance;

- Cor - Correlation of the percentage change in attendance of each individual location to the change in attendance of the workplace location;

- Max - Maximum percentage change in attendance;

- Min - Minimum percentage change in attendance;

- Dif - The difference between the maximum and minimum percentage change in attendance (= Max - Min).

Table 1: Changes in attendance of retail stores and recreation, pharmacies and grocery stores expressed as a percentage

\begin{tabular}{|l|r|r|r|r|r|r|r|r|r|r|r|r|}
\hline & \multicolumn{4}{|c|}{ Retail stores and recreation } & \multicolumn{4}{c|}{ Pharmacies and grocery stores } \\
\hline \multicolumn{1}{|c}{ Country } & Avg & SD & Cor & Max & Min & Dif & Avg & SD & Cor & Max & Min & Dif \\
\hline Bosnia and H. & -14 & 19 & 0,76 & 15 & -73 & 88 & 7 & 17 & 0,53 & 72 & -42 & 114 \\
\hline Serbia & -13 & 20 & 0,78 & 19 & -72 & 91 & 9 & 16 & 0,67 & 53 & -43 & 96 \\
\hline N. Macedonia & -19 & 17 & 0,71 & 9 & -67 & 76 & 2 & 12 & 0,42 & 37 & -32 & 69 \\
\hline Croatia & -15 & 25 & 0,57 & 32 & -80 & 112 & 7 & 17 & 0,59 & 58 & -51 & 109 \\
\hline Greece & -25 & 29 & 0,79 & 35 & -86 & 121 & 10 & 16 & 0,52 & 63 & -85 & 148 \\
\hline Bulgaria & -20 & 20 & 0,67 & 14 & -67 & 81 & 3 & 13 & 0,60 & 35 & -39 & 74 \\
\hline Romania & -21 & 18 & 0,66 & 9 & -73 & 82 & -1 & 15 & 0,63 & 30 & -52 & 82 \\
\hline
\end{tabular}

(Source: Authors)

Table 2: Changes in attendance of parks and places of rest and transit stations expressed as a percentage

\begin{tabular}{|l|r|r|r|r|r|r|r|r|r|r|r|r|}
\hline & \multicolumn{9}{|c|}{ Parks and places of rest } & \multicolumn{6}{|c|}{ Transit stations } \\
\hline \multicolumn{1}{|c}{ Country } & Avg & SD & Cor & Max & Min & Dif & Avg & SD & Cor & Max & Min & Dif \\
\hline Bosnia and H. & 6 & 25 & 0,03 & 74 & -46 & 120 & -15 & 16 & 0,77 & 15 & -68 & 83 \\
\hline Serbia & 10 & 31 & 0,35 & 78 & -65 & 143 & -16 & 20 & 0,90 & 21 & -75 & 96 \\
\hline N. Macedonia & 19 & 34 & 0,06 & 108 & -53 & 161 & -28 & 14 & 0,74 & 10 & -67 & 77 \\
\hline Croatia & 76 & 112 & 0,01 & 484 & -60 & 544 & -26 & 19 & 0,80 & 8 & -82 & 90 \\
\hline Greece & 55 & 71 & 0,43 & 317 & -67 & 384 & -30 & 22 & 0,88 & 10 & -86 & 96 \\
\hline Bulgaria & 20 & 41 & 0,32 & 118 & -59 & 177 & -10 & 21 & 0,79 & 34 & -65 & 99 \\
\hline Romania & -9 & 28 & 0,27 & 58 & -57 & 115 & -27 & 16 & 0,84 & 11 & -69 & 80 \\
\hline
\end{tabular}

(Source: Authors)

Table 3: Changes in attendance of workplaces and places of residence expressed as a percentage

\begin{tabular}{|l|r|r|c|r|r|r|r|r|r|r|r|r|}
\hline & \multicolumn{9}{|c|}{ Workplaces } & \multicolumn{5}{c|}{ Places of residence } \\
\hline \multicolumn{1}{|c}{ Country } & Avg & SD & Cor & Max & Min & Dif & Avg & SD & Cor & Max & Min & Dif \\
\hline Bosnia and H. & -16 & 13 & 1,00 & 14 & -55 & 69 & -1 & 7 & $-0,70$ & 23 & -14 & 37 \\
\hline Serbia & -24 & 14 & 1,00 & 16 & -62 & 78 & 3 & 7 & $-0,85$ & 26 & -7 & 33 \\
\hline N. Macedonia & -24 & 14 & 1,00 & 22 & -56 & 78 & 4 & 7 & $-0,62$ & 25 & -10 & 35 \\
\hline Croatia & -23 & 14 & 1,00 & 3 & -79 & 82 & 5 & 6 & $-0,83$ & 29 & -5 & 34 \\
\hline Greece & -26 & 15 & 1,00 & 4 & -84 & 88 & 7 & 8 & $-0,88$ & 33 & -5 & 38 \\
\hline Bulgaria & -25 & 11 & 1,00 & 3 & -68 & 71 & 4 & 6 & $-0,79$ & 23 & -6 & 29 \\
\hline Romania & -27 & 14 & 1,00 & 25 & -60 & 85 & 4 & 6 & $-0,76$ & 23 & -6 & 29 \\
\hline
\end{tabular}

(Source: Authors) 
Table 4 shows the correlation of the change in attendance of six statistical parameters of individual countries in relation to Serbia, which was taken as the reference country. This is because Serbia borders most of the Balkan countries, which were the subject of this analysis. The abbreviations in Table 4 for the observed statistical parameters are:

- Ret - retail and recreation;

- Phar - pharmacies and grocery stores;

- Park - city parks, national parks, public beaches, marinas, camps, dog parks;

- Traf - transit stations and public transport hubs;

- Work - workplaces;

- Hou - places of residence.

The correlation was first calculated for the time period from February 17 to May 18, 2020, which coincides with the period of the outbreak of the COVID-19 pandemic throughout Europe. Observing the obtained correlation coefficients, it can be concluded that they are generally higher than 0.75 during this period. This means that in this time period there was a close functional connection between the observed phenomena of changes in the mobility of people in Serbia and the other 6 Balkan countries. Only the parameter of pharmacy and food store in Bulgaria and Greece had a correlation coefficient in the interval from 0.5 to 0.75 , but we can say that here too there is a significant degree of connection between the concurrent phenomena.

Then, the correlation was calculated for the time period from March 2 to April 23, 2021, when a new large wave of patients with the COVID-19 virus appeared in Serbia. Observing the obtained correlation coefficients, it can be concluded that in this period, the change in the mobility of people in Serbia in relation to other parts of the Balkan countries behaved completely differently. The data between Serbia, Bulgaria and Romania had the highest degree of correlation. The data between Serbia and Croatia had the lowest degree of correlation, followed by Greece and Northern Macedonia. Based on this, it can be concluded that people in the beginning stages of the pandemic in Europe, as in all Balkan countries, behaved in a similar way when it come to mobility. On the other hand, it can be concluded that human mobility did not behave in the same way in all Balkan countries during the following waves of the virus.

Table 4: Correlation of changes in attendance of individual countries in relation to Serbia

\begin{tabular}{|l|c|c|c|c|c|c|c|c|c|c|c|c|}
\hline & \multicolumn{1}{|c|}{ Period February 17 to May 18, 2020 } & \multicolumn{3}{c|}{ Period March 2 to April 23, 2021 } \\
\hline \multicolumn{1}{|c}{ Country } & Ret & Phar & Park & Traf & Wor & Hou & Ret & Phar & Park & Traf & Wor & Hou \\
\hline Bosnia and H. & 0,98 & 0,89 & 0,79 & 0,97 & 0,92 & 0,97 & 0,68 & 0,62 & 0,84 & 0,71 & 0,41 & 0,75 \\
\hline N. Macedonia & 0,94 & 0,86 & 0,88 & 0,97 & 0,91 & 0,95 & 0,32 & 0,70 & 0,63 & 0,56 & 0,27 & 0,50 \\
\hline Croatia & 0,98 & 0,87 & 0,78 & 0,99 & 0,95 & 0,98 & 0,38 & 0,52 & 0,54 & 0,05 & $-0,1$ & 0,16 \\
\hline Greece & 0,95 & 0,63 & 0,76 & 0,92 & 0,89 & 0,94 & 0,67 & 0,68 & 0,49 & 0,80 & 0,33 & 0,75 \\
\hline Bulgaria & 0,93 & 0,72 & 0,85 & 0,93 & 0,86 & 0,91 & 0,76 & 0,74 & 0,85 & 0,86 & 0,68 & 0,85 \\
\hline Romania & 0,93 & 0,86 & 0,80 & 0,96 & 0,90 & 0,92 & 0,74 & 0,65 & 0,86 & 0,72 & $-0,2$ & 0,80 \\
\hline
\end{tabular}

We then transferred the data on the change in human mobility for the seven Balkan countries from MS Excel to a MS Access database, so that we could make various SQL queries over the input data. We did a grouping of data by years and calendar weeks. For each of the six observed locations of human mobility we calculated the average value for each week separately for 2020 and 2021. The five smallest percentage changes in the mobility of the "work" location are shown in Table 5 and Table 6 . The five smallest percentage changes in the mobility of the "transit station" location are shown in Table 7 and Table 8. The five largest percentage changes in mobility of the "places of residence" location are shown in 
Table 9 and Table 10. The five largest percentage changes in mobility of the "parks" location are shown in Table 11 and Table 12. The five smallest percentage changes in mobility of the "retail and recreation" location are shown in Table 13 and Table 14. The five smallest percentage changes the mobility of the "pharmacy and grocery stores" location are shown in Table 15 and Table 16.

The analysis of the presented data shows that the largest decline in human mobility in most countries in 2020 was at 13,14, 15, 16 and 17 weeks. On the other hand, in 2021, the biggest declines in human mobility were not concomitant for the different Balkan countries.

Table 5: Least percentage changes in workplaces mobility in 2020

\begin{tabular}{|c|r|c|r|r|r|r|r|r|r|r|r|r|r|}
\hline \multicolumn{2}{|c|}{ BH } & \multicolumn{2}{c|}{ Serbia } & \multicolumn{2}{c|}{ North Mac } & \multicolumn{2}{c|}{ Croatia } & \multicolumn{2}{c|}{ Greece } & \multicolumn{2}{c|}{ Bulgaria } & \multicolumn{2}{c|}{ Romania } \\
\hline$\%$ & week & $\%$ & week & \multicolumn{1}{c}{$\%$} & week & $\%$ & week & $\%$ & week & $\%$ & week & $\%$ & week \\
\hline-45 & 17 & -57 & 17 & -49 & 17 & -52 & 17 & -54 & 17 & -43 & 16 & -52 & 15 \\
\hline-48 & 16 & -60 & 16 & -50 & 14 & -56 & 16 & -55 & 16 & -44 & 15 & -52 & 17 \\
\hline-49 & 15 & -63 & 15 & -50 & 13 & -57 & 15 & -56 & 15 & -46 & 14 & -52 & 14 \\
\hline-51 & 14 & -68 & 14 & -51 & 15 & -61 & 14 & -57 & 14 & -49 & 13 & -53 & 53 \\
\hline-53 & 13 & -72 & 13 & -52 & 16 & -63 & 13 & -63 & 13 & -55 & 53 & -54 & 16 \\
\hline
\end{tabular}

(Source: Authors)

Table 6: Least percentage changes in workplaces mobility in 2021

\begin{tabular}{|c|r|c|r|l|r|r|r|r|r|r|r|r|r|}
\hline \multicolumn{2}{|c|}{ BH } & \multicolumn{2}{c|}{ Serbia } & \multicolumn{2}{c|}{ North Mac } & \multicolumn{2}{c|}{ Croatia } & \multicolumn{2}{c|}{ Greece } & \multicolumn{2}{c|}{ Bulgaria } & \multicolumn{2}{c|}{ Romania } \\
\hline$\%$ & week & \multicolumn{1}{c}{$\%$} & week & \multicolumn{1}{c}{$\%$} & week & \multicolumn{1}{c}{$\%$} & week & $\%$ & week & $\%$ & week & $\%$ & week \\
\hline-19 & 26 & -24 & 5 & -27 & 18 & -29 & 5 & -35 & 11 & -31 & 4 & -31 & 18 \\
\hline-22 & 2 & -25 & 4 & -29 & 17 & -30 & 4 & -35 & 13 & -32 & 15 & -31 & 6 \\
\hline-23 & 13 & -26 & 2 & -29 & 15 & -31 & 15 & -39 & 2 & -33 & 14 & -32 & 4 \\
\hline-24 & 15 & -26 & 12 & -30 & 16 & -34 & 3 & -43 & 8 & -34 & 19 & -32 & 3 \\
\hline-26 & 14 & -30 & 3 & -35 & 2 & -50 & 2 & -44 & 12 & -36 & 13 & -37 & 2 \\
\hline
\end{tabular}

(Source: Authors)

Table 7: Least percentage changes in transit stations mobility in 2020

\begin{tabular}{|c|c|c|c|c|c|c|c|c|c|c|c|c|c|}
\hline \multicolumn{2}{|c|}{$\mathrm{BH}$} & \multicolumn{2}{|c|}{ Serbia } & \multicolumn{2}{|c|}{ North Mac } & \multicolumn{2}{|c|}{ Croatia } & \multicolumn{2}{|c|}{ Greece } & \multicolumn{2}{|c|}{ Bulgaria } & \multicolumn{2}{|c|}{ Romania } \\
\hline$\%$ & week & $\%$ & week & $\%$ & week & $\%$ & week & $\%$ & week & $\%$ & week & $\%$ & week \\
\hline-50 & 17 & -57 & 17 & -57 & 17 & -67 & 17 & -64 & 16 & -50 & 16 & -60 & 16 \\
\hline-51 & 15 & -60 & 16 & -57 & 16 & -70 & 16 & -67 & 17 & -52 & 15 & -63 & 15 \\
\hline-53 & 16 & -63 & 15 & -58 & 15 & -70 & 15 & -70 & 15 & -52 & 17 & -64 & 17 \\
\hline-61 & 14 & -68 & 14 & -61 & 14 & -76 & 14 & -71 & 14 & -59 & 14 & -64 & 13 \\
\hline-66 & 13 & -72 & 13 & -65 & 13 & -81 & 13 & -78 & 13 & -62 & 13 & -66 & 14 \\
\hline
\end{tabular}

(Source: Authors)

Table 8: Least percentage changes in transit stations mobility in 2021

\begin{tabular}{|l|r|r|r|l|r|r|r|r|r|r|r|r|r|}
\hline \multicolumn{2}{|c|}{ BH } & \multicolumn{2}{c|}{ Serbia } & \multicolumn{2}{c|}{ North Mac } & \multicolumn{2}{c|}{ Croatia } & \multicolumn{2}{c|}{ Greece } & \multicolumn{2}{c|}{ Bulgaria } & \multicolumn{2}{c|}{ Romania } \\
\hline$\%$ & week & \multicolumn{1}{c}{$\%$} & week & \multicolumn{1}{c}{$\%$} & week & \multicolumn{1}{c}{$\%$} & week & $\%$ & week & $\%$ & week & $\%$ & week \\
\hline-24 & 4 & -24 & 5 & -33 & 5 & -36 & 6 & -50 & 11 & -22 & 2 & -35 & 6 \\
\hline-25 & 3 & -25 & 4 & -33 & 4 & -41 & 5 & -51 & 3 & -23 & 13 & -39 & 2 \\
\hline-26 & 16 & -26 & 2 & -34 & 12 & -42 & 4 & -52 & 12 & -26 & 5 & -41 & 3 \\
\hline-26 & 12 & -26 & 12 & -35 & 17 & -42 & 3 & -53 & 2 & -26 & 4 & -41 & 5 \\
\hline-31 & 13 & -30 & 3 & -37 & 13 & -50 & 2 & -59 & 8 & -26 & 3 & -41 & 4 \\
\hline
\end{tabular}

(Source: Authors) 
Table 9: Largest percentage changes in places of residence mobility in 2020

\begin{tabular}{|c|r|r|r|r|r|r|r|r|r|r|r|r|r|}
\hline \multicolumn{2}{|c|}{ BH } & \multicolumn{2}{c|}{ Serbia } & \multicolumn{2}{c|}{ North Mac } & \multicolumn{2}{c|}{ Croatia } & \multicolumn{2}{c|}{ Greece } & \multicolumn{2}{c|}{ Bulgaria } & \multicolumn{2}{c|}{ Romania } \\
\hline$\%$ & week & $\%$ & week & $\%$ & week & $\%$ & week & $\%$ & week & $\%$ & week & $\%$ & week \\
\hline 22 & 13 & 24 & 13 & 23 & 13 & 26 & 13 & 27 & 13 & 22 & 13 & 21 & 13 \\
\hline 20 & 14 & 23 & 14 & 20 & 14 & 24 & 14 & 24 & 14 & 20 & 14 & 21 & 14 \\
\hline 16 & 16 & 20 & 15 & 20 & 15 & 21 & 16 & 23 & 15 & 17 & 15 & 19 & 15 \\
\hline 16 & 15 & 18 & 16 & 19 & 16 & 21 & 15 & 22 & 17 & 16 & 17 & 19 & 17 \\
\hline 14 & 17 & 15 & 17 & 18 & 17 & 18 & 17 & 21 & 16 & 16 & 12 & 18 & 16 \\
\hline
\end{tabular}

(Source: Authors)

Table 10: Largest percentage changes in places of residence mobility in 2021

\begin{tabular}{|r|r|r|r|r|r|r|r|r|r|r|r|r|r|}
\hline \multicolumn{2}{|c|}{ BH } & \multicolumn{2}{c|}{ Serbia } & \multicolumn{2}{c|}{ North Mac } & \multicolumn{2}{c|}{ Croatia } & \multicolumn{2}{c|}{ Greece } & \multicolumn{2}{c|}{ Bulgaria } & \multicolumn{2}{c|}{ Romania } \\
\hline$\%$ & week & \multicolumn{1}{c}{$\%$} & week & \multicolumn{1}{c}{$\%$} & week & \multicolumn{1}{c}{$\%$} & week & $\%$ & week & $\%$ & week & $\%$ & week \\
\hline 2 & 2 & 7 & 2 & 7 & 2 & 14 & 2 & 14 & 8 & 9 & 13 & 9 & 2 \\
\hline-1 & 3 & 5 & 3 & 4 & 4 & 8 & 3 & 14 & 2 & 9 & 2 & 8 & 3 \\
\hline-2 & 13 & 5 & 12 & 3 & 3 & 8 & 5 & 13 & 12 & 8 & 3 & 8 & 4 \\
\hline-2 & 4 & 4 & 4 & 3 & 5 & 8 & 4 & 11 & 3 & 8 & 5 & 7 & 5 \\
\hline-3 & 5 & 3 & 5 & 2 & 17 & 6 & 7 & 10 & 11 & 7 & 4 & 4 & 6 \\
\hline
\end{tabular}

(Source: Authors)

Table 11: Largest percentage changes in parks mobility in 2020

\begin{tabular}{|c|r|r|r|r|r|r|r|r|r|r|r|r|r|r|}
\hline \multicolumn{2}{|c|}{ BH } & \multicolumn{2}{c|}{ Serbia } & \multicolumn{2}{c|}{ North Mac } & \multicolumn{2}{c|}{ Croatia } & \multicolumn{2}{c|}{ Greece } & \multicolumn{2}{c|}{ Bulgaria } & \multicolumn{2}{c|}{ Romania } \\
\hline$\%$ & week & $\%$ & week & $\%$ & week & $\%$ & week & $\%$ & week & $\%$ & week & $\%$ & week \\
\hline 63 & 33 & 67 & 33 & 97 & 33 & 440 & 33 & 269 & 33 & 106 & 33 & 50 & 33 \\
\hline 57 & 31 & 56 & 31 & 91 & 31 & 388 & 32 & 254 & 34 & 100 & 32 & 48 & 32 \\
\hline 49 & 32 & 54 & 35 & 80 & 30 & 381 & 31 & 216 & 32 & 99 & 34 & 46 & 34 \\
\hline 49 & 34 & 53 & 34 & 63 & 29 & 352 & 34 & 189 & 31 & 94 & 35 & 42 & 35 \\
\hline 44 & 30 & 48 & 37 & 63 & 32 & 329 & 30 & 180 & 35 & 94 & 30 & 38 & 37 \\
\hline
\end{tabular}

(Source: Authors)

Table 12: Largest percentage changes in parks mobility in 2021

\begin{tabular}{|c|r|r|r|r|r|r|r|r|r|r|r|r|r|}
\hline \multicolumn{2}{|c|}{ BH } & \multicolumn{2}{c|}{ Serbia } & \multicolumn{2}{c|}{ North Mac } & \multicolumn{2}{c|}{ Croatia } & \multicolumn{2}{c|}{ Greece } & \multicolumn{2}{c|}{ Bulgaria } & \multicolumn{2}{c|}{ Romania } \\
\hline$\%$ & week & $\%$ & week & $\%$ & week & $\%$ & week & $\%$ & week & $\%$ & week & $\%$ & week \\
\hline 33 & 26 & 48 & 27 & 81 & 27 & 273 & 27 & 169 & 27 & 70 & 27 & 28 & 27 \\
\hline 32 & 23 & 45 & 24 & 68 & 26 & 261 & 26 & 142 & 26 & 64 & 26 & 26 & 26 \\
\hline 30 & 25 & 44 & 26 & 65 & 25 & 173 & 25 & 114 & 25 & 49 & 19 & 19 & 24 \\
\hline 30 & 27 & 43 & 25 & 59 & 23 & 145 & 23 & 97 & 24 & 43 & 24 & 9 & 23 \\
\hline 27 & 24 & 40 & 22 & 56 & 20 & 132 & 24 & 94 & 23 & 38 & 20 & 9 & 22 \\
\hline
\end{tabular}

(Source: Authors)

Table 13: Least percentage changes in mobility in retail and recreation in 2020

\begin{tabular}{|c|r|c|r|r|r|r|r|r|r|r|r|r|r|}
\hline \multicolumn{2}{|c|}{ BH } & \multicolumn{2}{c|}{ Serbia } & \multicolumn{2}{c|}{ North Mac } & \multicolumn{2}{c|}{ Croatia } & \multicolumn{2}{c|}{ Greece } & \multicolumn{2}{c|}{ Bulgaria } & \multicolumn{2}{c|}{ Romania } \\
\hline$\%$ & week & $\%$ & week & \multicolumn{1}{c}{$\%$} & week & \multicolumn{1}{c}{$\%$} & week & $\%$ & week & $\%$ & week & $\%$ & week \\
\hline-59 & 17 & -51 & 17 & -54 & 16 & -61 & 17 & -67 & 16 & -50 & 17 & -57 & 16 \\
\hline-61 & 16 & -53 & 16 & -55 & 17 & -64 & 15 & -72 & 14 & -51 & 15 & -62 & 17 \\
\hline-61 & 15 & -60 & 15 & -57 & 15 & -65 & 16 & -73 & 15 & -54 & 12 & -63 & 15 \\
\hline-69 & 14 & -65 & 14 & -61 & 14 & -73 & 14 & -74 & 17 & -59 & 14 & -68 & 14 \\
\hline-72 & 13 & -69 & 13 & -67 & 13 & -78 & 13 & -80 & 13 & -64 & 13 & -68 & 13 \\
\hline
\end{tabular}

(Source: Authors) 
Table 14: Least percentage changes in mobility in retail and recreation in 2021

\begin{tabular}{|c|r|c|r|c|r|r|r|r|r|r|r|r|r|}
\hline \multicolumn{2}{|c|}{ BH } & \multicolumn{2}{c|}{ Serbia } & \multicolumn{2}{c|}{ North Mac } & \multicolumn{2}{c|}{ Croatia } & \multicolumn{2}{c|}{ Greece } & \multicolumn{2}{c|}{ Bulgaria } & \multicolumn{2}{c|}{ Romania } \\
\hline$\%$ & week & \multicolumn{1}{c}{$\%$} & week & \multicolumn{1}{c}{$\%$} & week & $\%$ & week & $\%$ & week & $\%$ & week & $\%$ & week \\
\hline-20 & 15 & -24 & 5 & -25 & 4 & -41 & 7 & -55 & 11 & -41 & 8 & -29 & 6 \\
\hline-20 & 5 & -24 & 4 & -28 & 13 & -42 & 3 & -56 & 2 & -45 & 4 & -32 & 2 \\
\hline-22 & 16 & -25 & 3 & -30 & 15 & -44 & 4 & -57 & 3 & -46 & 3 & -34 & 4 \\
\hline-24 & 14 & -33 & 13 & -35 & 16 & -45 & 5 & -57 & 12 & -47 & 5 & -34 & 3 \\
\hline-34 & 13 & -36 & 12 & -36 & 17 & -46 & 2 & -59 & 8 & -49 & 13 & -34 & 5 \\
\hline
\end{tabular}

(Source: Authors)

Table 15: Least percentage changes in mobility in pharmacies and grocery stores in 2020

\begin{tabular}{|c|r|c|r|c|r|r|r|r|r|r|r|r|r|}
\hline \multicolumn{2}{|c|}{ BH } & \multicolumn{2}{c|}{ Serbia } & \multicolumn{2}{c|}{ North Mac } & \multicolumn{2}{c|}{ Croatia } & \multicolumn{2}{c|}{ Greece } & \multicolumn{2}{c|}{ Bulgaria } & \multicolumn{2}{c|}{ Romania } \\
\hline$\%$ & week & $\%$ & week & $\%$ & week & $\%$ & week & $\%$ & week & $\%$ & week & $\%$ & week \\
\hline-25 & 16 & -15 & 17 & -12 & 16 & -28 & 15 & -12 & 17 & -19 & 15 & -31 & 18 \\
\hline-27 & 15 & -17 & 19 & -15 & 15 & -31 & 17 & -13 & 12 & -21 & 17 & -34 & 15 \\
\hline-28 & 17 & -24 & 15 & -22 & 17 & -33 & 16 & -14 & 15 & -24 & 12 & -36 & 17 \\
\hline-38 & 14 & -32 & 14 & -24 & 14 & -43 & 14 & -19 & 14 & -30 & 14 & -42 & 14 \\
\hline-40 & 13 & -38 & 13 & -31 & 13 & -48 & 13 & -34 & 13 & -34 & 13 & -43 & 13 \\
\hline
\end{tabular}

(Source: Authors)

Table 16: Least percentage changes in mobility in pharmacies and grocery stores in 2021

\begin{tabular}{|r|r|r|r|l|r|r|r|r|r|r|r|r|r|}
\hline \multicolumn{2}{|c|}{ BH } & \multicolumn{2}{c|}{ Serbia } & \multicolumn{2}{c|}{ North Mac } & \multicolumn{2}{c|}{ Croatia } & \multicolumn{2}{c|}{ Greece } & \multicolumn{2}{c|}{ Bulgaria } & \multicolumn{2}{c|}{ Romania } \\
\hline$\%$ & week & \multicolumn{1}{c}{$\%$} & week & \multicolumn{1}{c}{$\%$} & week & \multicolumn{1}{c}{$\%$} & week & \multicolumn{1}{c}{$\%$} & week & $\%$ & week & $\%$ & week \\
\hline 2 & 7 & 5 & 6 & -12 & 16 & 2 & 6 & -2 & 3 & -1 & 13 & -7 & 6 \\
\hline 1 & 6 & 4 & 7 & -15 & 15 & 1 & 3 & -2 & 5 & -2 & 2 & -8 & 2 \\
\hline-2 & 3 & -1 & 4 & -22 & 17 & -2 & 4 & -3 & 8 & -6 & 3 & -8 & 3 \\
\hline-5 & 4 & -1 & 3 & -24 & 14 & -4 & 2 & -5 & 12 & -8 & 4 & -10 & 4 \\
\hline-6 & 5 & -2 & 5 & -31 & 13 & -4 & 5 & -6 & 4 & -9 & 5 & -11 & 5 \\
\hline
\end{tabular}

(Source: Authors)

In this paper, we have shown how the mobility of people in the seven Balkan countries changed from 2020 to 2021. During this period, states took various measures to reduce the mobility of people and to force people to spend as much time as possible in their homes.

\section{CONCLUSION}

In this paper, we have shown how the mobility of people in the seven Balkan countries changed from 2020 to 2021. During this period, states took various measures to reduce the mobility of people and to require people to spend as much time as possible in their homes. By observing the derived data, we showed that the decrease in human mobility occurred with a similar intensity and during the same time periods in most of the observed countries. However, the enforcement measures of imprisonment, adopted by the governments of the observed countries, have had a high social and economic cost and it has become clear to everyone that these measures of social distancing cannot last indefinitely. Therefore, we believe that governments of all countries should continuously monitor these data, which we have also analyzed and constantly assess what interventions are necessary in order to maintain proper epidemiological restrictions.

The dataset utilized in this paper has a few limitations. First, people without smartphones and / or people who do not carry their devices when visiting the above-mentioned places are not 
included in Google's database. Second, the database only includes people who have Google Accounts and with the "Location History" setting enabled. We can conclude that most of the data for job locations, transportation, and housing facilities in this paper refer to changes in people's visits due to social distancing measures. On the other hand, the changes in the number of visitors to the "Park" location are primarily driven by the increase in the number of tourists in the summer months. The large percentage increase in mobility of people at the "Park" location in Croatia, Greece and Bulgaria is primarily caused by foreign tourists who came on vacation to these countries, so these foreign tourists are added to the mobility data of the local populations of the respective countries.

In 2020, social distancing led to a decline in gross domestic product (GDP) of the Balkan countries in this paper. We are optimistic that the data we obtained in this paper will be further elaborated alongside other daily interval data in these respective countries and thus permit further research efforts to be undertaken in other areas of social and economic realms of these Balkan nations.

\section{REFERENCES}

Carlos S., Francesco S., Spyridon S., Stefano M. I., Alessandro A., Dario T., MicheleV. (2020), „Measuring the impact of COVID-19 confinement measures on human mobility using mobile positioning data. A European regional analysis”, Safety Science, Volume 132, Article 104925.

Chan H., Skali A., Torgler B. (2020), „A global dataset of human mobility”, CREMA Working Paper, No. 2020-04, Center for Research in Economics, Management and the Arts (CREMA), Zürich.

Damjanović S., Katanić P., Krsmanović B. (2020), „Excel za ekonomiste“, Fakultet poslovne ekonomija, Bijeljina.

Google (2021), "COVID-19 Community Mobility Report", available at: https://www. google.com/covid19/mobility (accessed 3 July 2021).

Lapatinas A. (2020), „The effect of COVID-19 confinement policies on community mobility trends in the EU", Technical report by the Joint Research Centre, Publications Office of the European Union, Luksemburg.

Mendolia S., Stavrunova O., Yerokhin O. (2020), „Determinants of the Community Mobility during the COVID-19 Epidemic: The Role of Government Regulations and Information, IZA”, Institute of Labor Economics, Germany.

Moritz U. G. K., Chia-Hung Y., Bernardo G., Chieh-Hsi W., Brennan K., David M. P. (2020), „The effect of human mobility and control measures on the COVID-19 epidemic in China", SCIENCE Vol 368, pp. 493-497.

Simon P. ,Thomas R. (2021), „Social distancing beliefs and human mobility: Evidence from Twitter", PLOS ONE.

Stefano M. I., Carlos S., Francesco S., Spyros S., Dario T., Michele V. (2020), „Human mobility and COVID-19 initial dynamics", Nonlinear Dyn, pp. 493-497.

Sulyok M., Walker M. (2020), „Community movement and COVID-19: a global study using Google's Community Mobility Reports”, Cambridge University Press, England. 